\title{
PERAWATAN TALI PUSAT NEONATUS DAN MANFAAT TALI PUSAT TERBUKA
}

\author{
Djati Aji Nurbiantoro ${ }^{1 *}$, Febi Ratnasari ${ }^{2}$, Nuryani $^{3}$, Abdul Qohar $^{4}$, Achmad \\ Jaenuri $^{5}$, Dedi Supandi ${ }^{6}$, Asep Syaefullah ${ }^{7}$, Fajar Muharom $^{8}$, Jaelani ${ }^{9}$, \\ Julianus Zendrato ${ }^{10}$, Ilham Efendi ${ }^{11}$, Irwan Novendra ${ }^{12}$, \\ M Hasan Basri ${ }^{13}$, Payumi ${ }^{14}$, Sopian Solihin ${ }^{15}$, Suhandi ${ }^{16}$ \\ ${ }^{1-16}$ STIKES Yatsi Tangerang
}

Email Korespondensi: djatiaji@gmail.com

Disubmit: 07 Juli 2021

$\begin{array}{cr}\text { Diterima: } 21 \text { Juli } 2021 & \text { Diterb } \\ \text { DOI: https://doi.org/10.33024/jkpm.v5i2.4644 }\end{array}$

\begin{abstract}
ABSTRAK
Kematian neonatal akibat tetanus neonatorum dapat terjadi pada bayi, penyakit ini menginfeksi bayi baru lahir yang disebabkan oleh basil Clostridium tetani. Salah satu perawatan bayi baru lahir yang bertujuan untuk mencegah dan mengidentifikasi perdarahan atau infeksi secara dini adalah dengan melakukan perawatan tali pusat secara benar. Perawatan tali pusat yang dianjurkan adalah menggunakan perawatan tali pusat terbuka karena akan membantu pengeringan tali pusat lebih cepat. Tujuan kegiatan ini adalah dengan memberikan penyuluhan secara daring tentang perawatan tali pusat dengan baik dan benar dan manfaat tali pusat terbuka sehingga diharapkan dapat mengurangi resiko terjadinya infeksi pada bayi baru lahir. Metode penyuluhan secara online menggunakan presentasi power point mengenai perawatan tali pusat dan manfaat tali pusat terbuka serta demonstrasi cara melakukan perawatan tali pusat pada bayi baru lahir melalui aplikasi Zoom Meeting. Setelah dilakukan penyuluhan didapatkan peningkatan pengetahuan ibu-ibu tentang perawatan tali pusat dari $52,94 \%$ menjadi $83,33 \%$ dan manfaat tali pusat terbuka dari $54,90 \%$ menjadi $87,25 \%$.
\end{abstract}

Kata Kunci: perawatan tali pusat, manfaat tali pusat terbuka.

\section{ABSTRACT}

Neonatal death due to neonatal tetanus can occur in infants, this disease infects newborns caused by the bacillus Clostridium tetani. One of the newborn care that aims to prevent and identify bleeding or infection early is to perform proper care of the umbilical cord. The recommended umbilical cord care is to use an open umbilical cord treatment because it will help drain the cord faster. The purpose of this activity is to provide online counseling about proper and correct umbilical cord care and the benefits of an open umbilical cord so that it is expected to reduce the risk of infection in newborns. The online counseling method uses a power point presentation on umbilical cord care and the benefits of an open umbilical cord as well as a demonstration of how to perform umbilical cord care for newborns through the Zoom Meeting application. After counseling, it was found that the knowledge of mothers about umbilical cord care increased 
from $52.94 \%$ to $83.33 \%$ and the benefits of an open umbilical cord from $54.90 \%$ to $87.25 \%$.

Keywords: umbilical cord care, the benefits of an open umbilical cord.

\section{PENDAHULUAN}

Salah satu program pembangunan kesehatan pada periode 2019-2024 adalah meningkatkan status kesehatan dan gizi ibu dan anak. Kematian neonatal memberi kontribusi terhadap 59\% kematian bayi dimana salah satu penyebab terbesarnya ialah infeksi tetanus neonatorum yang disebabkan oleh basil Clostridium tetani. Penyakit ini menginfeksi bayi baru lahir melalui pemotongan tali pusat dengan alat yang tidak steril dan teknik perawatan tali pusat yang salah (Kemenkes, 2019).

Kematian neonatal akibat tetanus neonatorum berdasarkan data WHO tahun 2015 untuk negara-negara di Asia Tenggara sebanyak 581 bayi. Berdasarkan hasil Survei Demografi dan Kesehatan Indonesia (SDKI) tahun 2012 angka kematian neonatal menyumbang sebesar 19/1000 kelahiran hidup dari angka kematian bayi 32/1000 kelahiran hidup (Simanungkalit \& Sintya, 2019).

Kasus tetanus neonatorum di Indonesia tahun 2014 sebanyak 84 bayi dari 15 provinsi dengan mortalitas 54 bayi. Faktor risiko mortalitas tersebut antara lain perawatan tali pusat dengan alkohol, iodium, tradisional, serta perawatan tali pusat yang tidak diketahui caranya. Case Fatality Rate (CFR) tetanus neonatorum pada tahun 2014 sebesar 64,3\%, meningkat dibandingkan tahun 2013 sebesar 53,8\% (WHO, 2015).

Menurut Prawirohardjo, penanganan bayi baru lahir yang kurang baik akan menyebabkan kelainan-kelainan yang dapat menyebabkan cacat seumur hidup, bahkan kematian. Salah satunya adalah pencegahan terhadap infeksi yang dapat terjadi melalui tali pusat pada waktu pemotongan tali pusat, melalui mata, melalui telinga pada waktu persalinan atau pada waktu memandikan atau membersihkan bayi dengan bahan yang kurang bersih (Prawirohardjo, 2014).

Perawatan tali pusat diperlukan untuk mencegah tali pusat menjadi media perkembangbiakan mikroorganisme patogen : Staphylococcus aureus atau Clostridia. Teknik perawatan yang salah dapat menyebabkan infeksi tetanus neonatorum dimana hal tersebut dapat mempengaruhi lama pelepasan tali pusat (Reni et al., 2018).

Perawatan tali pusat sebaiknya dilakukan menggunakan perawatan tali pusat terbuka, meskipun ada juga yang menggunakan kasa kering untuk perawatannya. Perawatan tali pusat terbuka ialah perawatan tali pusat yang tidak diberikan perlakuan apapun. Tali pusat dibiarkan terbuka, tidak diberikan kasa kering maupun antiseptik lainnya. Pelepasan tali pusat dengan bantuan udara. Perawatan terbuka akan membantu pengeringan tali pusat lebih cepat karena pada tali pusat terdapat Jeli Wharton yang banyak mengandung air yang jika terkena udara akan berubah strukturnya dan secara fisiologis berubah fungsi menjadi padat dan mengeklem tali pusat secara otomatis sehingga menyebabkan aliran darah pada pembuluh darah didalam sisa tali pusat terhambat atau bahkan tidak mengalir lagi yang membuat tali pusat kering dan layu yang kemudian sisa tali pusat akan terlepas. Paparan udara menyebabkan penguapan pada kandungan air dalam Jeli Wharton dan pembuluh darah, sehingga kandungan air berkurang bahkan 
menghilang. Tali pusat mengalami mumifikasi kemudian mengering dan mengalami perubahan (Asiyah, 2017).

Sedangkan perawatan kasa kering yakni perawatan tali pusat yang menggunakan pembungkus berupa kasa kering (bersih atau steril), tali pusat tetap dijaga agar bersih dan kering sehingga tidak terjadi infeksi9). Kasa terbuat dari tenunan longgar, bermata besar dan dapat menyerap cairan dengan baik. Proses pelepasan tali pusat perlu difasilitasi oleh udara terbuka. Tali pusat tidak boleh ditutup rapat dengan apapun, karena akan membuatnya menjadi lembab. Selain memperlambat puputnya tali pusat, juga menimbulkan resiko infeksi (Reni et al., 2018)

Penelitian dari Dian Puspita Reni pada tahun 2018 yang berjudul perbedaan perawatan tali pusat terbuka dan kasa kering dengan lama pelepasan tali pusat pada bayi baru lahir diperoleh hasil responden kelompok kasus (perawatan kasa kering) berjumlah 40 bayi dengan lama pelepasan tali pusat 1-7 hari sebanyak 31 bayi dan 9 bayi yang $>7$ hari. Responden kelompok kontrol (perawatan tali pusat terbuka) berjumlah 40 bayi dengan lama pelepasan tali pusatnya 1-7 hari sebanyak 38 bayi dan 2 bayi yang $>7$ hari. Hasil penelitian ini sesuai juga dengan penelitian Azizah tahun 2015 yang berjudul Perbedaan Waktu Lepasnya Tali Pusat yang dibungkus dengan Kasa Steril dan Perawatan Terbuka pada Bayi di Wilayah Kerja Puskesmas Ambarawa Kabupaten Semarang, hasil penelitian ini menunjukkan bahwa waktu lepasnya tali pusat bayi yang dibungkus dengan kassa steril paling lama lepasnya (>7 hari) terdapat 4 responden (40\%) dan tali pusat yang lepasya normal (5-7 hari) sebanyak 6 responden (60\%). Hasil penelitian yang menggunakan perawatan terbuka waktu lepasnya paling cepat $(<5$ hari) terdapat 3 responden (30\%) dan tali pusat yang lepasnya normal (5-7 hari) terdapat 7 responden (70\%).

Terdapat berbagai hambatan dalam praktik perawatan tali pusat pada bayi neonatus. Kurangnya pengetahuan dari orang tua menyebabkan tali pusat jarang dibersihkan, padahal seharusnya dibersihkan sedikitnya dua kali dalam sehari atau ketika tali pusat terkena urin maupun feses. Bahkan tidak sedikit ibu primipara menggunakan metode jaman dahulu atas saran keluarga dalam perawatan tali pusat, misalnya pemakaian obat-obatan tradisional (bubuk atau daun-daunan dan sebagainya) dalam perawatan tali pusat, padahal hal tersebut dapat menyebabkan masuknya spora kuman tetanus ke dalam tubuh melalui tali pusat sehingga dapat mengakibatkan infeksi (Hidayah, 2021).

Dengan memberikan penyuluhan mengenai perawatan tali pusat neonatus dan manfaat tali pusat terbuka, diharapkan dapat meningkatkan pengetahuan dan pemahaman orang tua mengenai perawatan tali pusat pada bayi neonatus dan cara melakukan perawatan tali pusat terbuka, sehingga dapat terhindar dari infeksi yang bisa saja terjadi.

\section{MASALAH}

Masih sering terjadi ibu tali pusat neonatus diberi kassa dan ibu tidak berani mengganti kassa balutan hal tersebut dapat menyebabkan infeksi tali pusat karena dengan basah tersebut menimbulkan mudahnya masuk spora kuman tetanus, disebabkan kurangnya pengetahuan orang tua yang merupakan pasien-pasien kelolaan mahasiswa praktik profesi ners STIkes Yatsi Tangerang, Sehingga menjadi satu alasan dilakukannya penyuluhan tentang Perawatan tali pusat neonatus dan manfaat tali pusat terbuka. 


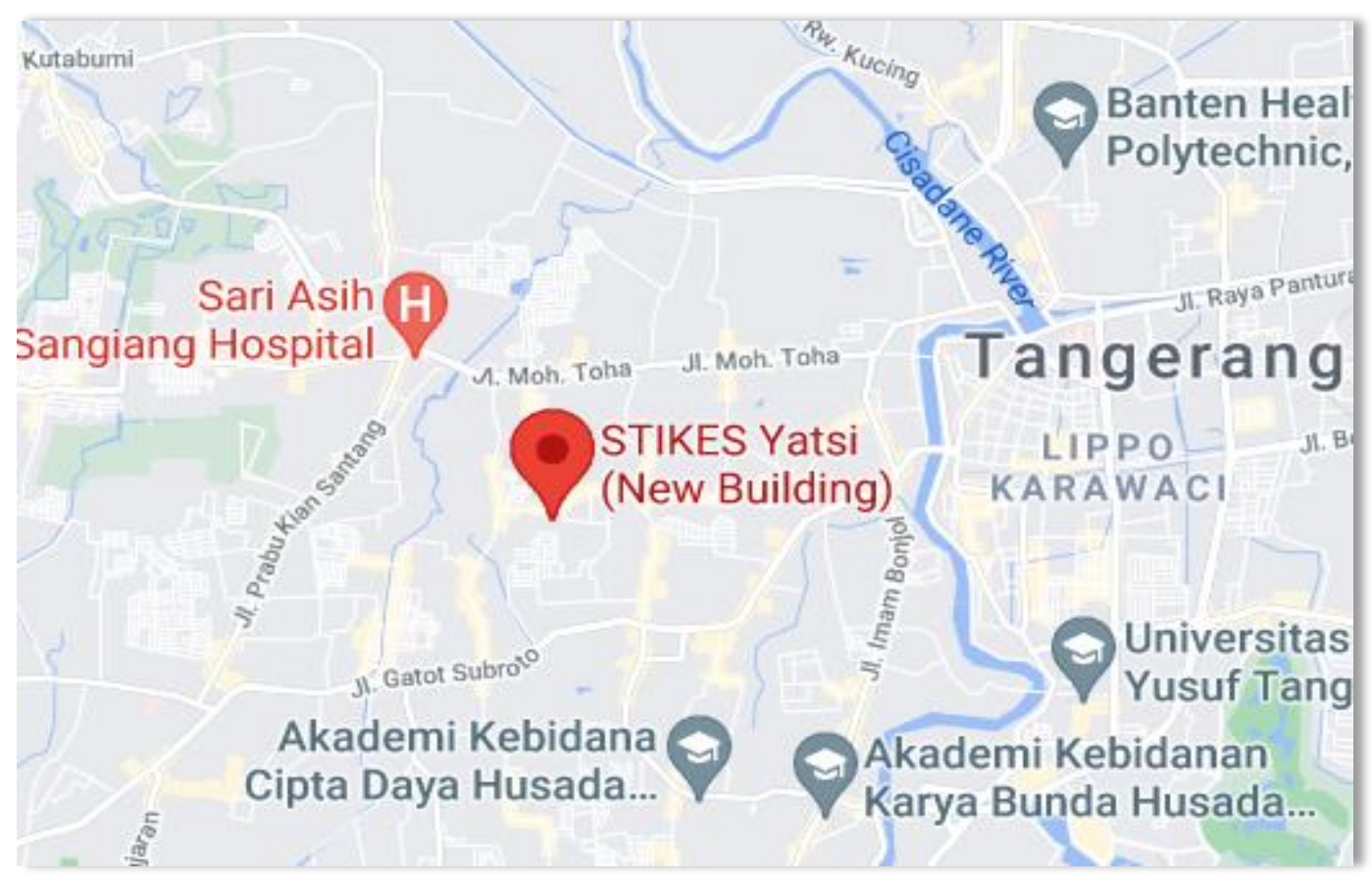

Gambar 1. Maps lokasi acara

\section{METODE}

a. Tahap persiapan

Tahap persiapan kegiatan ini dimulai dari pembuatan proposal kegiatan, materi penyuluhan dibuat secara singkat padat dan jelas dengan meminimalkan tulisan dan memberi gambar dalam power point hal tersebut untuk menarik perhatian sehingga memudahkan ibu untuk memahami materi, pembuatan link media dengan Zoom Meeting, mengingatkan kembali pada peserta untuk mengikuti acara.

b. Tahap pelaksanaan

Setelah semua peserta lengkap memasuki Zoom Meeting, ketua kelompok membuka acara dan dilanjutkan dengan presentasi secara jelas oleh narasumber serta dilanjutkan demonstrasi teknik perawatan tali pusat neonatus yang benar, serta demonstrasi perawatan tali pusat terbuka

1) Struktur

Kegiatan diikuti oleh 102 orang ibu dan calon ibu, peserta mengikuti kegiatan melalui Zoom Meeting sesuai dengan rencana yang dibuat. Kegiatan penyuluhan dilakukan dengan lancar dan materi yang disampaikan dapat dipahami oleh peserta.

2) Proses

Pelaksanaan kegiatan dilakukan pada hari Kamis tanggal 10 Juni 2021 dimulai dari pukul $09.00 \mathrm{~s} / \mathrm{d} 11.00$ WIB sesuai dengan jadwal yang telah dibuat 


\section{HASIL DAN PEMBAHASAN}

Menimbang kondisi pandemi dan masih berlakunya Pemberlakukan Pembatasan Kegiatan Masyarakat (PPKM) berskala Mikro di wilayah Tangerang Raya, maka kegiatan penyuluhan dilaksanakan di rumah masing-masing responden pada tanggal 10 Juni 2021 pukul 09.00 s/d 11.00 WIB dengan jumlah peserta 102 orang ibu dan calon ibu.

Tabel 1. Data Responden Berdasarkan Usia

\begin{tabular}{ccc}
\hline Usia & $\mathbf{n}$ & Persentasi (\%) \\
\hline 20-25 tahun & 32 & $31,37 \%$ \\
$25-30$ tahun & 39 & $38,24 \%$ \\
$30-35$ tahun & 21 & $20,59 \%$ \\
35-40 tahun & 10 & $9,80 \%$ \\
\hline Jumlah & $\mathbf{1 0 2}$ & $\mathbf{1 0 0 \%}$ \\
\hline
\end{tabular}

Tabel 1 menunjukkan presentasi responden berdasarkan kelompok umur di dapatkan dari yang terbanyak usia 25-30 tahun sebanyak 39 orang $(38,24 \%)$, usia 20-25 tahun sebanyak 32 orang(31,37\%), usia 30-35 tahun sebanyak 21 orang $(20,59 \%)$ dan usia $35-40$ tahun sebanyak 10 orang $(9,8 \%)$.

Tabel 2. Data Responden Berdasarkan Tingkat Pendidikan

\begin{tabular}{ccc}
\hline Tingkat Pendidikan & $\mathbf{n}$ & Persentasi (\%) \\
\hline Sarjana & 45 & $44,12 \%$ \\
SMA & 47 & $46,08 \%$ \\
SMP & 10 & $9,80 \%$ \\
\hline Jumlah & 102 & $100 \%$ \\
\hline
\end{tabular}

Dari tabel 2 menunjukan presentasi responden berdasarkan tingkat pendidikan didapatkan hasil dari yang terbanyak yaitu tingkat pendidikan SMA sebanyak 47 orang $(46,08 \%)$, tingkat pendidikan Sarjana sebanyak 45 orang $(44,12 \%)$ dan tingkat pendidikan SMP sebanyak 10 orang $(9,80 \%)$.

Tabel 3. Data responden berdasarkan jumlah anak

\begin{tabular}{ccc}
\hline Jumlah Anak & $\mathbf{n}$ & Persentasi (\%) \\
\hline$>1$ & 18 & $17,65 \%$ \\
1 & 33 & $32,35 \%$ \\
Calon Ibu & 51 & $50,00 \%$ \\
\hline Jumlah & 102 & $100 \%$ \\
\hline
\end{tabular}

Dari tabel 3 menunjukan tentang jumlah anak yang telah dimiliki oleh responden diperoleh hasil dari yang terbanyak yaitu yang belum mempunyai anak (calon ibu) sebanyak 51 orang (50\%) telah mempunyai 1 oranga anak sebanyak 33 orang $(32,35 \%)$ dan yang telah mempunyai lebih dari 1 orang anak (>1) sebanyak 18 orang $(17,65 \%)$. 
Tabel 4. Data responden berdasarkan pengetahuan ibu tentang perawatan tali pusat neonatus dengan benar sebelum penyuluhan

\begin{tabular}{ccc}
\hline Perawatan Tali Pusat & $\mathbf{n}$ & Persentasi (\%) \\
\hline Baik & 54 & $52,94 \%$ \\
Cukup & 23 & $22,55 \%$ \\
Kurang & 25 & $24,51 \%$ \\
\hline Jumlah & 102 & $100 \%$ \\
\hline
\end{tabular}

Dari tabel 4 menunjukan tentang pengetahuan ibu tentang perawatan tali pusat sebelum dilakukan penyuluhan yaitu yang pengetahuannya baik sebanyak 54 responden $(52,94 \%)$, yang pengetahuannya kurang sebanyak 25 responden $(24,51 \%)$ dan yang pengetahuannya cukup sebanyak 23 orang responden $(22,55 \%)$.

Tabel 5. Data responden berdasarkan pengetahuan ibu tentang manfaat tali pusat terbuka sebelum penyuluhan

\begin{tabular}{ccc}
\hline $\begin{array}{c}\text { Manfaat Tali Pusat } \\
\text { Terbuka }\end{array}$ & $\mathbf{n}$ & Persentasi (\%) \\
\hline Baik & 56 & $54,90 \%$ \\
Cukup & 18 & $17,65 \%$ \\
Kurang & 28 & $27,45 \%$ \\
\hline Jumlah & 102 & $100 \%$ \\
\hline
\end{tabular}

Dari tabel 5 menunjukan tentang pengetahuan ibu tentang manfaat tali pusat terbuka sebelum dilakukan penyuluhan yaitu yang pengetahuannya baik sebanyak 56 responden $(54,90 \%)$, yang pengetahuannnya kurang sebanyak 28 responden $(27,45 \%)$ dan yang pengetahuannya cukup sebanyak 18 orang responden $(12,65 \%)$.

Setelah dilakukan penyuluhan tentang perawatan tali pusat neonatus, menjelaskan tentang proses membersihkan tali pusat dengan benar serta menjelaskan tentang manfaat tali pusat terbuka, sehingga didapatkan peningkatan pengetahuan ibu.

\section{Tabel 6}

Data responden berdasarkan pengetahuan ibu tentang perawatan tali pusat neonatus dengan benar setelah penyuluhan

\begin{tabular}{ccc}
\hline Perawatan Tali Pusat & $\mathbf{n}$ & Persentasi (\%) \\
\hline Baik & 85 & $83,33 \%$ \\
Cukup & 17 & $16,67 \%$ \\
Kurang & 0 & $0 \%$ \\
\hline Jumlah & 102 & $100 \%$ \\
\hline
\end{tabular}

Dari tabel 6 menunjukan tentang pengetahuan ibu tentang perawatan tali pusat setelah dilakukan penyuluhan yaitu yang pengetahuannya baik sebanyak 85 responden $(83,33 \%)$, yang pengetahuannya cukup sebanyak 17 responden $(16,67 \%)$ dan tidak ada ibu yang pengetahuannya kurang $(0 \%)$. 
Tabel 7

Data responden berdasarkan pengetahuan ibu tentang manfaat tali pusat terbuka Setelah penyuluhan

\begin{tabular}{ccc}
\hline $\begin{array}{c}\text { Manfaat Tali Pusat } \\
\text { Terbuka }\end{array}$ & $\mathrm{n}$ & Persentasi (\%) \\
\hline Baik & 89 & $87,25 \%$ \\
Cukup & 13 & $12,75 \%$ \\
Kurang & 0 & $0 \%$ \\
\hline Jumlah & 102 & $100 \%$ \\
\hline
\end{tabular}

Dari tabel 7 menunjukan tentang pengetahuan ibu tentang manfaat tali pusat terbuka sebelum dilakukan penyuluhan yaitu yang pengetahuannya baik sebanyak 89 responden $(87,25 \%)$, yang pengetahuannya cukup sebanyak 13 responden $(12,75 \%)$ dan tidak ada ibu yang pengetahuannya kurang $(0 \%)$.

Kegiatan evaluasi tersebut dilakukan dengan memberikan pertanyaan melalui google form yang diisi oleh responden. Evaluasi tersebut dilakukan untuk mengetahui tingkat pemahaman ibu tentang perawatan tali pusat dan manfaat tali pusat terbuka.
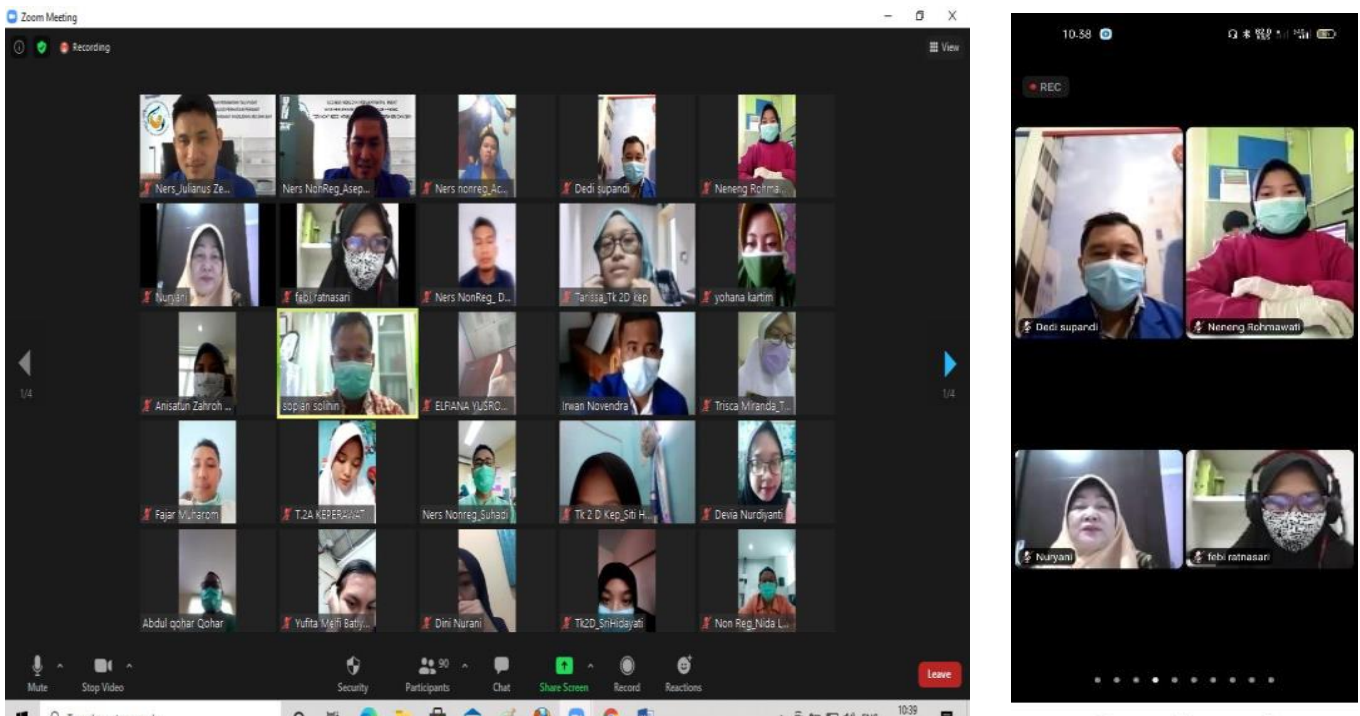

Gambar 2. Penyuluhan tentang perawatan tali pusat dan manfaat tali pusat terbuka

Poin utama dalam merawat tali pusat adalah menjaga kebersihan sebelum melakukan perawatan tali pusat dengan cuci tangan, serta menjaga bersih dan kering pada tali pusat dan sekitarnya. Dampak positif perawatan tali pusat secara baik dan benar adalah tali pusat cepat kering dan pupus pada hari ke-5 dan hari ke-7 tanpa komplikasi. Perawatan tali pusat yang tidak benar akan memperlambat puputnya tali pusat, dan juga dapat meningkatkan resiko terjadinya infeksi tali pusat yang disebut dengan Tetanus Neonaturum yang disebabkan oleh bakteri Clostridium Tetani dan dapat menyebabkan kematian.

Perawatan tali pusat bisa dilakukan melalui 2 cara yaitu perawatan tali pusat dengan kassa steril yaitu pertahankan sisa tali pusat dalam keadaan terbuka agar terkena udara dan ditutupi dengan kassa steril secara longgar. Melipatpopok di bawah sisa tali pusat. Jika tali pusat terkena kotoran atau tinja cuci dengan sabun dan air bersih lalu keringkan dengan menggunakan kassa. 
Tali pusat harus dibersihkan sedikitnya dua kali dalam sehari. Kassa yang membungkus tali pusat diganti setelah bayi mandi. Tali pusat yang melekat di perut bayi, akan disisakan beberapa senti oleh dokter atau bidan agar tali pusat bisa dipotong dan diikat. Sisanya ini akan dibiarkan hingga pelan-pelan menyusut dan mengering, lalu terlepas dengan sendirinya. Tali pusat tidak boleh ditutup rapat dengan menggunakan apapun, karena menyebabkan tali pusat menjadi lembab. Selain memperlambat lepasnya tali pusat, penutupan tali pusat juga akan menyebabkan resiko infeksi. Bila terpaksa ditutup, tutup dan ikatlah dengan longgar pada bagian atas tali pusat dengan mempergunakan kassa steril dan pastikan bagian pangkal tali pusat terkena udara dengan bebas (Kemenkes, 2017).

Dan yang kedua adalah perawatan tali pusat terbuka, merupakan perawatan tali pusat yang membiarkan tali pusat secara terbuka tanpa kassa atau bahkan alkohol dan povidone iodin. Begitu bayi lahir, tali pusat sudah tidak diperlukan lagi sehingga harus dipotong, diikat atau dijepit, kemudian dilakukan perawatan tali pusat. Saat dipotong tali pusat terlepas dari suply darah dari ibu. Pemotongan dan pengikatan tali pusat menyebabkan pemisahan fisik antara ibu dan bayi. Setelah dilakukan pengikatan tali pusat kemudian dilakukan perawatan tali pusat dengan perawatan terbuka. Tujuan dari perawatan adalah untuk mencegah infeksi dan meningkatkan pemisahan tali pusat dari perut. Setelah bayi lahir tali pusat dipotong, secara mendadak tali pusat tidak mendapat aliran darah, akan menjadi kering. Pengeringan dan pelepasan tali pusat dipermudah karena terpapar udara. Dalam 24 jam warna putih tali pusat menghilang dan berubah menjadi kuning kecoklatan dan mengering atau kehitaman kering dan kaku, sehingga mempercepat pelepasan tali pusat. (Azizah, 2015).

Perawatan tali pusat secara terbuka memiliki cara yang lebih praktis dan efisien, tanpa menggunakan bahan apapun dalam perawatannya. Perawatan terbuka hanya membiarkan tali pusat itu terpapar udara sehingga dapat mempercepat proses pengeringan dan pelepasan tali pusat (Azizah, 2015).

Di masyarakat masih sering ditemukan bayi dengan keadaan tali pusat dengan kasa yang masih lengket dengan tali pusat dan tali pusat yang berbau (tanda -tanda infeksi tali pusat) yang disebabkan ibu tidak berani mengganti balutan tali pusat. Kondisi seperti ini dapat terjadi salah satunya disebabkan oleh pengetahuan ibu nifas. Pengetahuan ibu nifas yang baik tentang perawatan tali pusat belum tentu melaksanakan perawatan talipusat dengan baik karena sikap tidak berani melakukan perawatan tali pusat. Hal ini menyebabkan ibu nifas tidak melakukan perawatan tali pusat dengan baik. Seharusnya pengetahuan ibu nifas yang baik sejalan dengan kemampuan dan keterampilan yang baik pula dalam melakukan perawatan tali pusat (Erawati et al., 2020).

Kegiatan penyuluhan kesehatan ini terdiri dari pengisian soal pre-test, penyampaian materi mengenai perawatan tali pusat dan manfaat tali pusat terbuka, demonstrasi cara perawatan tali pusat, dilanjutkan sesi tanya jawab dan diakhiri dengan pengisian soal post-test. Peserta mengikuti pemateri mulai mendengarkan presentasi, menyaksikan demonstrasi dan mengikuti sesi tanya jawab. Peserta yang hadir dalam penyuluhan tampak sangat antusias mengikuti penyuluhan dari awal sampai akhir. Pengetahuan peserta saat evaluasi diketahui meningkat. 


\section{KESIMPULAN}

Kesimpulan dari uraian kegiatan pengabdian masyarakat tersebut antara lain dengan dilakukan penyuluhan maka terdapat peningkatan pengetahuan ibuibu tentang perawatan tali pusat dengan benar yang awalnya hanya $52,94 \%$ naik menjadi $83,33 \%$ serta terdapat peningkatan pengetahuan ibu tentang manfaat perawatan tali pusat terbuka yang awalnya dari $54,90 \%$ menjadi $87,25 \%$.

\section{DAFTAR PUSTAKA}

Asiyah, N. (2017). Perawatan Tali Pusat Terbuka Sebagai Upaya Mempercepat Pelepasan Tali Pusat. I(I), 29-36.

Azizah, R. A. (2015). Perbedaan Waktu Lepasnya Tali Pusat Yang Dibungkys Dengan Kassa Steril dan Perawatan Terbuka Pada Bayi di Wilayah Kerja Puskesmas Ambarawa Kabupaten Semarang. Akademi Kebidanan Ngudi Waluyo.

Erawati, A. D., Puspitasari, D., \& Cahyaningsih, O. (2020). Pengetahuan Ibu Nifas tentang Perawatan Tali Pusat di Wilayah Puskesmas Ambarawa Kabupaten Semarang. Jurnal IImu Kesehatan Masyarakat, 9(01), 43-47. https: / /doi.org/10.33221/jikm.v9i01.476

Hidayah, Y. N. (2021). Hubungan Pengetahuan Tentang Perawatan Bayi Baru Lahir Dengan Penerimaan Peran Baru Pada Ibu Primipara di Desa Tugusari Kabupaten Jember. Universitas Muhammadiyah Jember.

Kemenkes. (2017). Asuhan Persalinan Normal dan Inisiasi Menyusu Dini. JNPKKR.

Kemenkes. (2019). Rencana Strategis Kementerian Kesehatan Tahun 2019-2024. Kementerian Kesehatan RI.

Prawirohardjo. (2014). Buku Acuan Pelayanan Kesehatan Maternal Dan Neonatal. PT. Bina Pustaka.

Reni, D. P., Nur, F. Ti., Cahyanto, E. B., \& Nugraheni, A. (2018). Perbedaan Perawatan Tali Pusat Terbuka Dan Kasa Kering Dengan Lama Pelepasan Tali Pusat Pada Bayi Baru Lahir. PLACENTUM: Jurnal Ilmiah Kesehatan Dan Aplikasinya, 6(2), 7. https://doi.org/10.20961/placentum.v6i2.22772

Simanungkalit, H. M., \& Sintya, Y. (2019). Perawatan Tali Pusat Dengan Topikal Asi Terhadaplama Pelepasan Tali Pusat. Jurnal Kebidanan Malahayati, 5(4), 364-370. https://doi.org/10.33024/jkm.v5i4.1552

WHO. (2015). Causes Under-Five Mortality 2015. www.who.int\%0A/gho/child_health/mortality/causes/en/\%0A 